Project Document

\title{
A new frontier for Caribbean convergence: integration without borders
}

\author{
Winston Dookeran \\ Minister of Foreign Affairs of Trinidad and Tobago
}

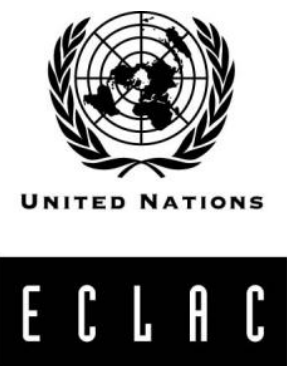


The views expressed in this document, which has been reproduced without formal editing, are those of the author and do not necessarily reflect those of the Organization.

This address was presented at the headquarters of the United Nations Economic Commission for Latin America and the Caribbean in Santiago, Chile, during an official visit to the Republic of Chile by the Honourable Winston Dookeran, Minister of Foreign Affairs of Trinidad and Tobago.

LC/CAR/W.6

Copyright $@$ United Nations, April2014. All rights reserved

Printed at United Nations, Santiago, Chile. 


\section{Contents}

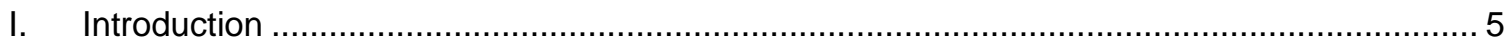

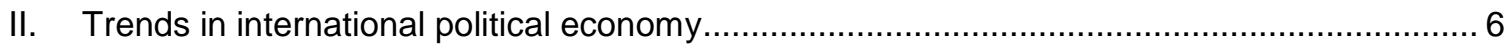

A. Emerging trade and economic architecture .......................................................... 7

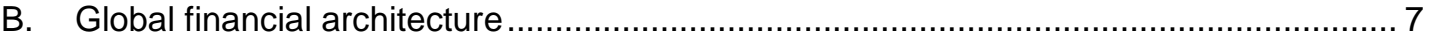

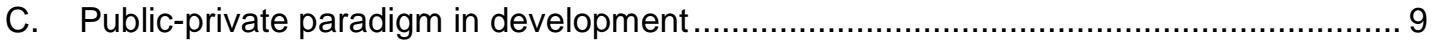

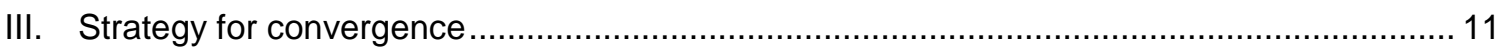

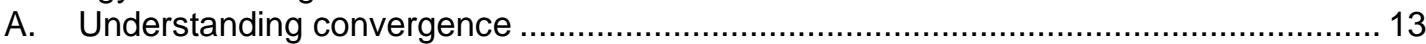

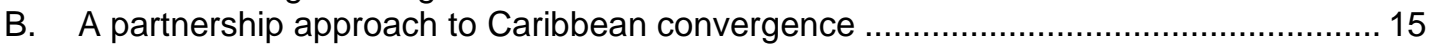

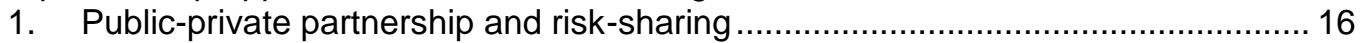

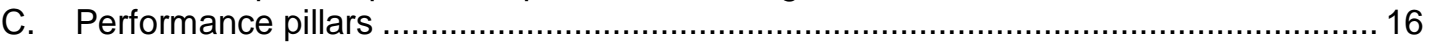

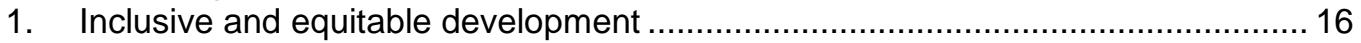

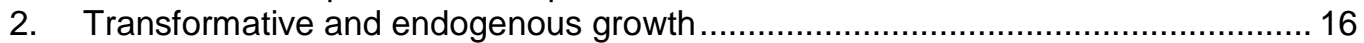

3. Innovative and entrepreneurial competitiveness ............................................ 17

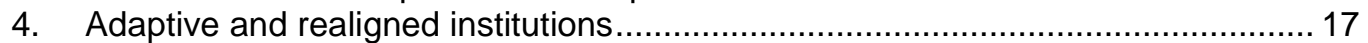

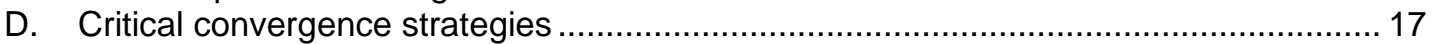

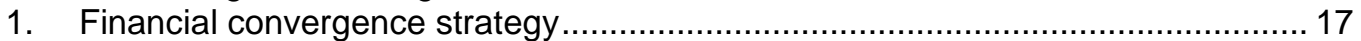

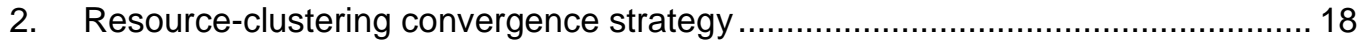

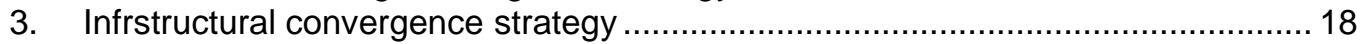

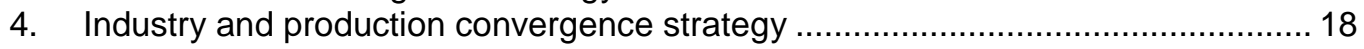

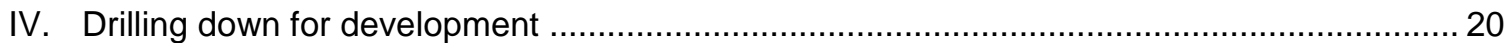

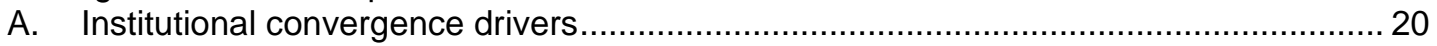

B. Twelve-point action proposal for Caribbean convergence ......................................... 21

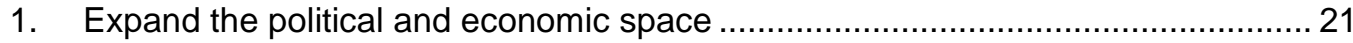

2. Develop a Caribbean Sea convergence integrated transport

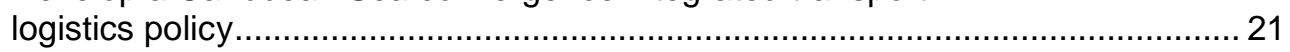

3. Establish a Caribbean Sea convergence capital mobility

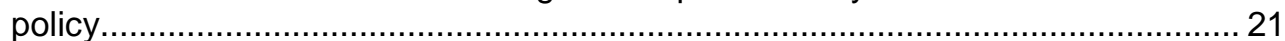

4. Develop Caribbean Sea convergence energy and food security policies

5. Implement a Caribbean Sea convergence financial policy 
C. The role of Trinidad and Tobago in Caribbean convergence .......................................2 22

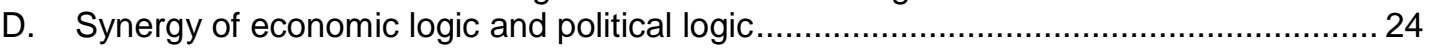

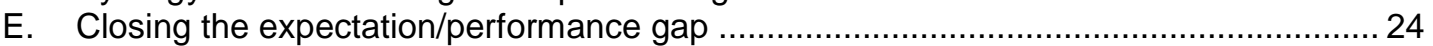




\section{Introduction}

Today, forty years since its birth, the Caribbean integration has reached its limit. ${ }^{12}$ Consequently, there is urgent need to respond to the current realities and emerging global trends - which require greater engagement from the public, students, academics and policymakers - in moving the Caribbean Community towards a new trajectory of Caribbean convergence. The immediate concern is to devise ways of improving the convergence process among Latin American and Caribbean countries. This convergence process will have to be sensitive to both current and emerging global dynamics.

This paper presents the roadmap of a new trajectory towards Caribbean convergence, sensitive to both current and emergent regional and global trends. It begins in Section I by identifying the emerging international political and economic trends that provide a backdrop against which the discussion on Caribbean convergence is squarely placed. Section II discusses the need for a new strategy of convergence, and provides the conceptual framework of Caribbean convergence. Section III spells out the pillars, strategies and delivery mechanisms of Caribbean convergence, and highlights the role of Trinidad and Tobago in this process. The paper concludes by pointing out the urgent need for a regional synergy of economic logic and political logic.

${ }^{1}$ The present paper was conceptualized by Winston Dookeran and Akhil Malaki and presented at the Retreat for Foreign Ministers on "Caribbean Convergence" at Monos Island, Chaguaramas, Trinidad and Tobago on 14 May 2013.

${ }^{2}$ Caribbean Community member States recently celebrated the fortieth anniversary of the signing of the Treaty of Chaguaramas on 4 July 2013. 


\section{Trends in international political economy}

\section{A. Emerging trade and economic architecture}

The future of the international political economy is definitely going to be different — both in dynamics and architecture. For example, the pronouncements of global groups like the BRICS countries (Brazil, Russia, India, China and South Africa), and regional convergence, as in the case of the Association of Southeast Asian Nations (ASEAN), are examples of alternative ways of dealing with global development. More importantly, the expansion of the Group of Seven Industrialized Countries, or G7, (the United States of America, Japan, Germany, France, the United Kingdom, Italy, and Canada) to the - now - Group of 20 (G20), is concrete evidence of what is to be expected.

Emerging markets have become the economic powerhouses in the current global economy and key contributors to global economic growth - even after the global financial crisis. They have become major consumers with increases in national savings and growth in their capital markets. These emerging markets have recorded $48 \%$ growth in exports and have become central to global production networks with increasing specialization.

Interestingly, South-South and North-South trade is overtaking the traditional North-North trade architecture. This emerging trade architecture is buttressed by the growth and expansion of multinationals from emerging markets. The growing human resources, technological capabilities and Government policies have contributed to a shift in the global comparative advantage away from developed countries. In addition, emerging market economies hold almost three-fourths of sovereign wealth fundsFirst paragaraph has no indentation, but should be justified. ${ }^{3}$

${ }^{3}$ For more on emerging markets and global political economy, see World Bank (2012), 'The Role of Emerging Market Economy Demand during the Post-2005 Boom', Contribution from the World Bank to the G20 Commodity Markets Sub Working Group 71266, April 2012; World Bank (2011), Multipolarity: The New Global Economy, World Bank, 2011; Hanson, Gordon (2012), 'The Rise of Middle Kingdoms: Emerging Economies in Global Trade', NBER Working Paper 17961, March 2012. [Online]: http://www.nber.org/papers/w17961; Fornes, Gaston (2012), 'Emerging Markets: The Markets of the Future', MPRA Paper No. 42315, September 2012, [Online] at: http://mpra.ub.uni-muenchen.de/42315/; Aizenman, Joshua (2007): 'Large hoarding of international reserves and the emerging global economic 


\section{B. Global financial architecture}

The global financial architecture of the twenty-first century has also undergone dramatic change. The emerging financial architecture is multipolar, with the yuan renminbi (RMB) asserting its role alongside the dollar and the euro. Sovereign wealth funds from emerging markets are fuelling outward foreign direct investment and growth in bilateral investment treaties. Furthermore, there have been significant changes to the governance structure of the global financial system of the Basel III wherein a number of rulemaking institutions have extended membership to BRICS.

Brazil, India and China were accepted as members by the International Organization of Securities Commissions (IOSCO) in 2009. Argentina, Brazil, China, India, Indonesia, Mexico, Russia, Saudi Arabia, South Africa, South Korea, Spain and Turkey were accepted as new members of the Financial Stability Board. The Basel Committee on Banking Supervision (BCBS) expanded its membership to include Brazil, China, India, South Korea, Mexico, Australia and Russia. In 2009, Argentina, Indonesia, Saudi Arabia, South Africa, Turkey, Hong Kong and Singapore were included. In this way, all G20 countries were included as members of the Basel Committee. ${ }^{4}$ The Goldman Sachs Report Dreaming with BRICS: The Path to 2050 has predicted that BRICS could be larger than the G6 by $2039 .^{5}$

\section{Public-private paradigm in development}

John G. Ruggie rightly observed that there has been a historic development of a newly emergent global public domain or global civil society constituted by interactions among non-State as well as State actors. This has, in many ways, altered the traditional public-private relationship into a wider context. The emerging public domain 'permits the direct expression and pursuit of a variety of human interests, not merely those mediated - filtered, interpreted, promoted - by States.' This new global domain of civil society organizations (CSOs) does not seek to replace the State but rather, seeks 'to embed systems of governance in broader global frameworks of social capacity and agency that did not previously exist.'

Public-private partnerships are emerging to provide information-sharing, reciprocity, building and diffusion of norms, and supply of public goods in an era of governance failures. The new rights advocacy, for example, is advancing economic and social human rights as well as civil and political rights, as essential to understanding rule-making in the global public domain. Increasingly, social and

architecture' Working Papers No. 07-08 2007, Santa Cruz Center for International Economics, [Online]: http://hdl.handle.net/10419/64101; Zoellick, Robert B (2009), 'After the Crisis', Development Outreach, World Bank Institute, December 2009.

${ }^{4}$ See Griffith-Jones, Stephany (2009), 'Perspectives on the Governance of Global Financial Regulation'. Paper presented at the Commonwealth Finance Ministers Meeting, Limassol, Cyprus, 30 September - 3 October, 2009. The Commonwealth Secretariat.

${ }^{5}$ For more on the BRICS countries, see: Lawson, Sandra (2003), "Dreaming with BRICS: The Path to 2050." CEO Confidential Goldman Sachs Report, October 2003 2003/12 (2003); and the article "The Way Forward - From Policy discussions to delivering tangible benefits, BRICS nations plan on wider cooperation" published online in The Hindu on 21 February 2013, which emphasized the need to move from "policy discussions to delivering tangible benefits." See [online]: http://www.thehindu.com/news/cities/Delhi/the-way-forward/article4435519.ece 
economic policy decisions are being taken in a global public domain in which national/transnational boundaries are blurred and the public domain includes non-State actors. ${ }^{6}$

The ongoing post-2015 Millennium Development Goals' discussions acknowledge that weak governance is one of the reasons why the benefits of development are neither shared equally nor sustainable over time. The emerging post-2015 consensus seems to recognize the common-but differentiated - responsibilities of governmental and non-governmental actors for progress shared by all. The idea of just governance of this framework is to ensure the inclusion and participation of the most marginalized peoples and is very clear on the issue of inclusiveness.

There is now both recognition and empirical evidence that governance has remained one of the foremost deficits in achieving the Millennium Goals: the lack of people's voices in policy design, implementation and monitoring along the whole line of accountability, from the global to the national to the local level, coupled with poor coordination across sectors, within and between Governments, has constrained progress. ${ }^{7}$

The recognition and upsurge of civil society actors has, in fact, created a fertile environment for a new type of governance based on public-private partnerships and networking. The unique - and new-is that private, civil-society actors are serving, or delivering, essentially public goods that were hitherto under the scope of national governments. Even the very idea of public goods is now undergoing conceptual changes as it becomes public in consumption. The recent debate on global public goods (GPG), which demonstrates clearly the narrowing of the public/private divide, has now entered the discourse on governance, and is likely to be included in the post-2015 agenda of the United Nations Millennium Development Goals. ${ }^{8}$

The emerging public-private paradigm also involves new forms of partnership between public and private sectors. The role of the private sector and private institutions in economic growth has become critical to the idea of convergence. It calls for innovative forms of partnership between States and the private sector, and global and regional development finance institutions in integrated production. In short, the emerging public-private partnership demonstrates the trend towards a more inclusive political economy.

${ }^{6}$ Ruggie, John Gerard (2004), 'Reconstituting the Global Public Domain: Issues, Actors and Practices'. JFK School of Government, Harvard University. Faculty Research Working Paper Series 2004, RWP04031, pp. 24-31. See also: Andonova, L. B. (2006), 'Globalization, Agency, and Institutional Innovation: The Rise of Public-Private Partnerships in Global Governance'. Goldfarb Center Working Paper No. 2006-004; Bernhardt, B. (2009), Public Authority beyond the State: Reconsidering the Public-Private Dimensions of State and Non-state Forms of Governance. One Earth Future Foundation Working Paper; Nelson, P. and Dorsey, E. (2007), 'New Rights Advocacy in a Global Public Domain'. In European Journal of International Relations, 13, pp. 187-216.

${ }^{7}$ See, Beyond 2015 (2013), Just Governance: A critical cornerstone for an equitable and human rightscentered sustainable development agenda post-2015, February, available [online] at: http://www.cesr.org/article.php?id=1450; United Nations Development Programme, 'Global Consultation on Governance and the Post-2015 Framework: Concept Note', 2013, available [online] at: http://www.worldwewant2015.org/node/277876; United Nations Population Fund 2013, 'Building Bridges among Faith-Based Organizations and Secular Development Practitioners' available [online] at: http://www.unfpa.org/culture/fbo.html; Hulme, D. and Wilkinson, R. (2012), Brave new world: global development goals after 2015, BWPI Working Paper 168, Brooks World Poverty Institute, University of Manchester.

${ }^{8}$ See Salamon, Lester, Sokolowski, Wojceich and List, Regina (2003), Global Civil Society: An Overview, Center for Civil Society Studies, Institute for Policy Studies, The Johns Hopkins University; Kaul, I. (2013), Global Public Goods: A Concept for Framing the Post-2015 Agenda, Discussion Paper \# 2/2013, German Development Institute. 


\section{From multilateralism to multitrak diplomacy}

This changing architecture in international political economy - discussed above - has also induced changes in the way nation States are conducting their relations with other State and non-State actors. In this changing environment, traditional diplomacy has its limitations. Today's issues are far too complex, and the various components of global political economy - conflicts, trade, finance, governance, and so on - too intertwined. The process of globalization - once seen as creating so many benefits and advantages for the world - has created, to a significant degree, new risks and dangers for all members of the international community. President Obama's recent visit to the Far East - short though it was-was, symbolically, very important for the change in the world order, as the United States of America has begun to embrace a new strategic partnership with a group of Asian countries that are well on the path towards economic convergence of some sort.

The Caribbean needs to move beyond traditional diplomacy to embrace multitrack diplomacy, the kind that recognizes the need to adapt to the contemporary realities of globalization, in which the fundamental issues around burden-sharing call for creative thinking and bold political judgment. In that context, the traditional methods of multilateralism cannot be relied upon to handle world diplomacy. The concept of multilateralism refers to the constitutive rules that order relations in given domains of international life: in other words, their architectural dimension.

Multilateralism coordinates relations among three or more States on the basis of generalized principles on conduct: that is, principles which specify appropriate conduct for a class of actions, without regard to the particularistic interests of the parties or the strategic exigencies that may exist in any specific occurrence. ${ }^{9}$ It is a belief, or ideology, rather than a straightforward state of affairs ... a deep, organizing principle of international life. ${ }^{10}$ Multilateralism is also understood as three or more actors engaging in voluntary and (more or less) institutionalized cooperation governed by norms and principles, with rules that apply (more or less) equally to all. ${ }^{11}$

It is a different world today. The number of players has increased markedly and, similarly, the web of interests and influence has become significantly more complex and interrelated. In the midst of a tough global economy, already haemorrhaging jobs and with vital sectors facing collapse in some areas, the drive to liberalize trade might have been weakened by the widespread desire among key countries, not merely to reverse the loss of jobs, but to keep the ones they already had. Trinidad and Tobago has begun to search deliberately for a new method of reinforcing multilateralism and has recognized the need to operate on a multitrack policy on diplomacy.

At this point in time, the choices are not clear. What is clear is that we must be engaged in the deliberations as these choices pursue their own paths. So, Trinidad and Tobago has really been engaged in multitrack diplomacy, whether it be at the United Nations, in bilateral relationships with countries, or in relationships globally with the emerging order: the fundamental objective now being, at all times, to move into the diplomacy of engagement.

The Caribbean as a group, and Trinidad and Tobago in particular, has opted too often for the policy of abstention. Abstention, viewed as a deliberate act, is a good thing: but abstention, viewed as

${ }^{9}$ Ruggie, John Gerard (1992), 'Multilateralism: the Anatomy of an Institution', International Organization, Vol. 46, No. 3 (Summer, 1992), pp. 571.

10 Caporoso, James A (-), 'International Relations Theory and Multilateralism: The Search for Foundations', International Organization 46, 3, Summer 1, pp. 603.

${ }^{11}$ Bouchard, Caroline and Peterson, John (2009), 'Conceptualizing Multilateralism', MERCURY Working Paper Work Package 1, December 2009, p. 7, available [online] at: http://www.mercuryfp7.net/index.php?id=10072. 
an opted-out act, is not. In today's world, this approach must change: the Caribbean cannot resort to the comfort of opting-out by abstention. Caribbean States need to be in the trenches, dealing with the complexities and devising constructive solutions.

At times, in trying to pursue a position of neutrality, abstention may be used as a deliberate act. The role of Trinidad and Tobago, as a small economy in the global environment, is to have the power both of convening other like-minded countries and, at the same time, of having a moral influence on the issues before us: and that is the fundamental principle on which we hope to build our diplomacy for the future.

In the case of Latin America, Trinidad and Tobago took the deliberate decision, as a Government, to join in the Latin American process that is now gaining momentum and that will mould the character of the integration processes in the region, alongside the diplomatic possibilities that can emerge as the Caribbean and Latin America work together. These processes encompass not just Governments, but also public-private partnerships across Latin America and the Caribbean.

Very specifically, Trinidad and Tobago has begun to open its doors to Latin American institutions: apart from joining the Brazilian Constituency - now comprising Brazil, Colombia, the Dominican Republic, Ecuador, Guyana, Haiti, Panama, Suriname, and Trinidad and Tobago - some years ago in the International Monetary Fund (IMF) and the World Bank, Trinidad and Tobago has recently agreed to join the Andean Development Bank as a full member. We have been a member for some time, but not a full member. This is a significant step, now that the integration of Latin America and the Caribbean is being funded by sources and resources from within Latin America and the Caribbean itself. The Andean Development Bank is a major departure from our reliance on the traditional multilateral institutions like the World Bank and the Inter-American Development Bank (IDB).

In addition, Trinidad and Tobago has agreed, at all levels, whether it be at the meeting of Ministers or at any other level, to be engaged in a new Latin American bonding. There is no doubt: Trinidad and Tobago is as Latin American in its geopolitical position as it is North American in the politics in which it has been engaged. In that context, our country's role is not to try and create anything different, but to ensure that any opportunity for this due diplomacy is one in which we engage in a positive way.

Conversations have been initiated with some smaller economies of the world, not only at the United Nations where Trinidad and Tobago participated in the forum on small States, but also at the World Bank where, for some time, Trinidad and Tobago has shared the forum on small States. A common platform is emerging from our bilateral discussions, between countries that are relatively small - much larger than Trinidad and Tobago, in some cases - but equally vulnerable to the changing architecture of the global political economy, in which the future remains rather unclear.

All that Trinidad and Tobago can do, at this stage, is to pursue a constructive policy of neutrality while, at the same time, ensuring that we are fully engaged; then, at the appropriate time, we can seek the support of the Caribbean Community (CARICOM) and sister countries in the wider Caribbean, including the Association of Caribbean States, in order to make some impact on global diplomacy in the future. It is in that context that the Government of Trinidad and Tobago supports the initiative that is being taken in the Latin American process. 


\section{Strategy for convergence}

Against the backdrop of the preceding discussion on the nature of the emerging global political economy, the Caribbean regional strategy in adapting to new global realities needs to be reconsidered. What should be the CARICOM response to these global shifts? Is there any viable strategy for moving forward? The ensuing discussion provides a new strategy of 'Caribbean Convergence' as the regional strategy for moving forward. ${ }^{12}$

CARICOM, although a political concept at its inception, has become an economic project. Caribbean institutions are 'enslaved by the methods of the past' and in 'paralysis in thinking.' It is no longer economically workable. The logic of economics that drove this project has been trade and markets. ${ }^{13}$

Caribbean integration confronts pitfalls and, without change, will disappear. ${ }^{14}$ In the current context, the forces of integration elsewhere in the world are being shaken by the roots, because integration is multitrack in nature - it is local, regional and international all at the same time. ${ }^{15}$ Furthermore, CARICOM as an economic project was mostly designed for the integration of markets and expansion of trade, with negligible attention to the most important economic and market actor, the private sector.

It is, therefore, not surprising that economic integration in the Caribbean is still a work-inprogress; and, what has been accomplished so far has not impacted significantly on regional economic

\footnotetext{
${ }^{12}$ The strategy of Caribbean Convergence was jointly conceptualized by Akhil Malaki, Senior Lecturer, Department of Government, University of the West Indies, Mona Campus, Jamaica, and The Honourable Winston Dookeran, Minister of Foreign Affairs, Government of Trinidad and Tobago. This strategy was developed into a policy paper: Dookeran, W. and Malaki, A. (2013), "A New Frontier for Caribbean Convergence" presented at the Retreat for Foreign Ministers on Caribbean Convergence at Monos Island, Chaguanas, Trinidad and Tobago, May 14, 2013. Much of the discussion here is drawn from that paper.

13 Dookeran, W., (2012), 'Caribbean Convergence: Revisiting Caribbean Integration.' Remarks for the Opening Ceremony, Caribbean Development Roundtable, Guyana, May 30, 2012.

${ }^{14}$ Comment by the former Prime Minister of Jamaica, P.J. Patterson, in his keynote speech at the launch of Sir Sridath Ramphal's Caribbean Challenges on June 18, 2012, Jamaica.

${ }^{15}$ Dookeran, W. (2012), Plenary Speech at the Caribbean Growth Forum Launch Event, June 18-19, 2012, Kingston, Jamaica.
} 
development. ${ }^{16}$ The nature of the exercise of sovereignty has posed a constant challenge and, therefore, the urgency to be innovative and flexible. ${ }^{17}$

The leadership in the region has 'put the gears of CARICOM single market in neutral and the gears of CARICOM single economy into reverse' resulting in the countries in the region drawing steadily away from each other. ${ }^{18}$ The real issue now is about fresh thinking and innovative ways of moving the process beyond CARICOM integration to Caribbean Sea Convergence (CSC). This convergence process, similar to the ASEAN model, offers greater flexibility, scope and benefits for the Caribbean Sea economies in responding to emerging global challenges to capture a new frontier space.

The agenda for a new political economy was identified in 2008 with the call for fresh thinking in Caribbean development. ${ }^{19}$ Accordingly, this strategy framework provides a new political and economic life in the process of Caribbean integration. The initiative is not to supplant the Caribbean integration movement, but to reinforce it with some innovative ways of moving the process that is understood as 'Caribbean Convergence' forward, to create an 'Economy of the Caribbean Sea'. However, before discussing Caribbean Sea Convergence itself, we need to place it in its rightful context by providing a brief overview of the background against which this notion of convergence has emerged.

The idea of Caribbean Convergence has been put forth and discussed on various occasions over the last couple of years, with positive feedback. The feedback has provided the input for the framework developed here, which is an innovative approach to reviving CARICOM in a different context, to make it more relevant and to capture a new frontier of Caribbean convergence.

Some concerns were recently raised by $\operatorname{ECLAC}^{20}$ regarding the mechanisms of convergence and the modalities by which to engage the private sector in CARICOM. The framework addresses these concerns, firstly through the partnership approach and, more specifically, through fostering public-private partnerships across the Economy of the Caribbean Sea.

The Trinidad and Tobago chapter of the Caribbean Growth Forum identified three themes (investment climate, logistics and connectivity, skills and productivity) to be addressed through public-private partnerships. ${ }^{21}$ The policy paper prepared for the Monos Island meeting of Foreign Ministers to discuss Caribbean Convergence was already ahead in addressing the issues through its twelve-point action programme (discussed further on). ${ }^{22}$ It is a matter of necessity-and urgencythat this process of Caribbean Sea Convergence be made to happen.

Economic production capability and growth in the Caribbean needs stable, affordable and sustainable energy. High oil prices both threaten and create a new opportunity for Caribbean integration and economic growth. High and volatile oil prices create challenges for economic growth

16 Girvan, Norman (2010), 'Caribbean Community: The Elusive Quest for Economic Integration'. Caribbean Development Bank, 2010.

17 Benn, Dennis (2012), 'Foreword'. In Ramphal, Sridath, Caribbean Challenges, Hansib Publications, London, 2012. pp. 11-14.

${ }^{18}$ Ramphal, Sridath (2012), 'Vision and leadership: The infinite unity of Caribbean needs'. In Ramphal, Sridath, Caribbean Challenges, Hansib Publications, London, 2012. pp. 157-173.

19 Dookeran, Winston \& Malaki, Akhil (2008), Leadership and Governance in Small States: Getting Development Right. Verlag Dr. Muller, Saarbrucken, Germany, 2008, pp. 149-156.

${ }^{20}$ Alleyne, Dillon, (2013), 'Preliminary comments on the concept paper "Introducing the Convergence Model of Integrated Production", Symposium to discuss the paper: "Introduction to the Convergence Model of Integrated Production". ECLAC Subregional Headquarters for the Caribbean, Trinidad and Tobago, May 9, 2013.

${ }^{21}$ Caribbean Growth Forum. Trinidad and Tobago Chapter. May 8, 2013.

${ }^{22}$ Dookeran, W. and Malaki, A. (2013), "A New Frontier for Caribbean Convergence" presented at the Retreat for Foreign Ministers on Caribbean Convergence, Monos Island, Chaguanas, Trinidad and Tobago, May 14, 2013. 
and integration based on productive economic activities. Climbing oil prices and their volatility also make it evident that alternatives to liquid hydrocarbon - the main fuel in most of the Caribbean - must be found.

For the next few years, the alternative is natural gas. In the long term, the alternative must be renewable energy. In the Caribbean, solar and wind energy is quickly becoming a lower-cost option, with geothermal electricity having the ability to provide base-load power in the eastern Caribbean. Unleashing the full potential of natural gas or of renewable energy is hampered by small, fragmented energy markets in the Caribbean, interconnecting through undersea power cables, gas pipelines or virtual pipelines transporting liquid natural gas on small container ships appropriate for markets in the Caribbean.

These markets must also be integrated, by implementing harmonized policies and predictable - and consistent - regulatory frameworks. This is the new Caribbean integration paradigm: in which there is convergence of economies of scale with capital. There is no other choice for the energy future and, hence, the economic growth of the Caribbean.

In the search for more economic space, Caribbean convergence must be examined in the context of an ever-changing global arena. Furthermore, this new economic convergence process will have to confront the political challenges and the redesign of its economic and financial architecture. The challenge is to drill down for development: to move from the macroeconomic framework into the 'drilling down' framework - into the 'making-it-happen' framework - into the 'getting results' framework.

All this is happening in the context of satisfying the new equilibrium between the political debates, the requirements of the time, and economic reality. Public policy must get the logics of politics and the logics of economics in alignment with one other.

\section{A. Understanding convergence}

The nature and characteristics of small Caribbean economies make them extremely sensitive to global trends. The success of these economies is dependent on how flexible they are in adapting and adjusting to changing global conditions. There are some glimpses of the future in current discussions, from the United Nations Economic Commission for Latin America and the Caribbean (ECLAC) ${ }^{23}$ to the emerging post-2015 development framework. ${ }^{24}$ There will be a greater role for public-private partnerships driven by non-State entities. ${ }^{25}$ The concern over the effects of global financial rulemaking on small- and medium-sized economies has already been raised. ${ }^{26}$

Furthermore, the global economic and financial architecture has changed from G7 to-nowG20, which has its own implications for the Caribbean. ${ }^{27}$ Even the African Caribbean and Pacific

${ }^{23}$ United Nations Economic Commission for Latin America and the Caribbean (ECLAC), Opportunities for Convergence and Regional Cooperation. High-level Summit of Latin America and the Caribbean. February 21-23, 2010, Cancun, Mexico; ECLAC, 'The Politics of Global Financial Regulation Rulemaking.' ECLAC Brief 2012, Washington Office.

${ }^{24}$ ECLAC, The Caribbean Forum: Shaping a Sustainable Development Agenda to Address the Caribbean Reality in the Twenty-first Century (Draft Report), Bogota, 5-6 March, 2013. Adam, M.F. and Niels, K., Practice Makes Perfect? The European Union's Engagement in Negotiations on a Post-2015 Framework for Development. DIIS Report 2013:04.

${ }^{25}$ Andonova, L. B. (2004), 'Globalization, Agency, and Institutional Innovation: The Rise of Public-Private Partnerships in Global Governance'. Goldfarb Center Working Paper No. 2006-004.

${ }^{26}$ ECLAC, (2012), 'The Politics of Global Financial Regulation Rulemaking.' ECLAC Brief 2012, Washington Office.

${ }^{27}$ Bissessar, Kamala Persad, Prime Minister of the Republic of Trinidad and Tobago, at the United Nations General Assembly Thematic Debate: "The United Nations and Global Economic Governance", April 15, 2013. 
States (ACP)-European Union Joint Parliamentary Assembly relations will undergo fundamental changes in the future: there is a tacit understanding among Europeans that the ball is in the ACP court in terms of defining and determining their own future as a group and their relationship vis-à-vis the European Union. ${ }^{28}$

There are definite gains in converging to respond to emerging global changes. Expanding the economic space provides the scope for leverage in production and competitiveness. The Caribbean Sea has already been recognized as a special space by the Association of Caribbean States (ACS), which has even established a Caribbean Sea Commission. ${ }^{29}$ The draft Declaration of Haiti endorses:

...the initiative of the Republic of Trinidad and Tobago to promote economic advancement in the region through the creation of a convergence process structured on the facilitation of capital movement, the integration of capital markets, the development of transportation infrastructure and the reorientation of the policies of the international financial institutions to equip regional economies better to withstand exogenous shocks. ${ }^{30}$

ECLAC calls clearly for broader regional forums to foster cooperation that can unlock the synergies of different subregions and progress toward gradual convergence of regional economic space. ${ }^{31}$ Caribbean convergence is the strategy to move the Caribbean integration process into the direction of convergence. It is another, better, way of capturing the future through a new frontier for Caribbean convergence.

The rationale behind the new Caribbean integration strategy is the endeavour towards a convergence of economies of scale with capital. The strategy draws upon practical convergence, as opposed to integration, taking place in the world today. The focus is on converging economies regardless of structures, because structural integration is a problem everywhere - whether in Latin America, the Caribbean or Europe. Therefore, convergence of 'economic spaces' is a response to the limitations of the CARICOM integration process and development challenges. Accordingly, convergence is a shift from a physically limited plane to an open economic space. ${ }^{32}$

In the first instance, convergence means expanding CARICOM to include the Dominican Republic, the Dutch and French islands, and French Guiana. Convergence is not about creating something new, nor is it opposed to CARICOM integration. Rather, it is about bringing new political and economic dynamics to the process of Caribbean integration: by reworking the existing framework in innovative and flexible ways (the logic of politics) to cope with changing global realities, and by redefining the modalities of execution.

This convergence framework defines an innovative form of public-private partnership within the 'Economy of the Caribbean Sea' with a focus on production integration, distribution and competitiveness (the logic of economics) supporting trade and markets. Therefore, convergence is moving from the limitations of Caribbean integration towards a new frontier for Caribbean convergence. Convergence is about adding future value to the workings of the integration process,

28 German Development Institute (DIE), 2013, 'ACP-EU Relations beyond 2020: Exploring European Perceptions'. Briefing Paper \# 11/2013, German Development Institute.

${ }^{29}$ Association of Caribbean States (ACS) (2013), Fifth Summit of Heads of State and /or Government of the Association of Caribbean States (ACS) (2013), Draft Plan of Action, April 17, 2013.

${ }^{30}$ The Association of Caribbean States (ACS), Draft Declaration of Haiti (2013). Preparatory Meeting for the VI Extraordinary Meeting of the ACS Ministerial Council, Peton Ville, Haiti, 23-24 April, 2013.

31 United Nations Economic Commission for Latin America and the Caribbean (ECLAC), (2010), Opportunities for Convergence and Regional Cooperation. High-level Summit of Latin America and the Caribbean. February 21-23, 2010, Cancun, Mexico.

${ }^{32}$ Dookeran, Winston (2012), Power, Politics and Performance: A Partnership Approach to Development. Ian Randle, 2012, Kingston. 
and supporting the structures built over the last forty years. This is in line with the call for building regional capacity to address global challenges. ${ }^{33}$

\section{B. A partnership approach to Caribbean convergence ${ }^{34}$}

Convergence strategies and partnerships go together. The discussions on 'Regional Economic Integration: Caribbean Convergence and Competitiveness' at the launch of the Caribbean Growth Forum (2012) set the tone for action and change. Two important issues were recognized: the political imperative of convergence, and the need for appropriate corrective mechanisms that aligned the needs of the local with the regional. It was also noted that the problem with Caribbean integration lay in its failure to implement. The larger Caribbean space was heterogeneous, with contrasting economic structures that were politically sensitive. The discussions concluded that the rationale for integration and/or convergence should be, firstly, political, meaning political collaboration (that is, political logic).

The new perception of convergence needs to be understood as a new economic space where there is partnership, not just across the Caribbean Sea space, but also between the public and private sectors. It is the forging of a right partnership toward productive efficiency. Convergence, therefore, implies partnership (inclusiveness and cooperation) among public and private actors in the economies of the Caribbean Sea, emphasizing equality and equity as integral components.

The aim of such a partnership is to achieve the goals of production integration, competitiveness and distribution across this economic space (i.e. the economic logic), in addition to trade and markets. According to this economic logic, convergence is not just about enlargement of markets and trade, it is about making the Caribbean resilient and globally competitive, to capitalize on the future.

The partnership approach is a stakeholder approach that provides Caribbean Sea States with a practical way forward in aligning each national agenda with the Economy of the Caribbean Sea - that is, the harmonization of a Caribbean Sea agenda. Central to this regional space is the alignment of the logic of politics (inclusiveness, cooperation) with the logic of economics (production integration, competitiveness and distribution).

Creating the Caribbean Sea economy is, foremost, a politically-driven process requiring a partnership approach. Therefore, the immediate policy requirement is granting membership to the Dominican Republic. The French- and Dutch-speaking islands have applied for associate membership and should be granted membership. Initiatives need to be taken to incorporate French Guiana into the CARICOM framework. These are issues to be resolved, and not issues to prohibit.

\section{Public-private partnership and risk-sharing}

In the public-private partnership approach, risk-sharing is an important concept that requires identifying what risks can be borne by different partners. The catalytic role of the State is important in funding risk which cannot be funded by the market itself. We need to look at State institutions to ascertain where the State can be the purchaser of public benefits to ensure better distribution of welfare. Another area of risk-sharing is to leverage the strength of one sector and combine that with new strategic partnerships. At present, the emergence of optimal transactional structures is evident, as

\footnotetext{
${ }^{33}$ United Nations Economic Commission for Latin America and the Caribbean (ECLAC), (2010), Opportunities for Convergence and Regional Cooperation. High-level Summit of Latin America and the Caribbean. February 21-23, 2010, Cancun, Mexico.

${ }^{34}$ See Dookeran, W., Power, Politics and Performance: A Partnership Approach to Development. Ian Randle, 2012, Kingston.
} 
the world is moved not by targets as much as by transactions; therefore, the transactions that have to take place will require a substantial amount of new modelling. The consumer/client demands that the processes function in a here-and-now world.

\section{Performance pillars ${ }^{35}$}

In order to be sustainable, the Caribbean Sea economy has to be built on the following four pillars:

\section{Inclusive and equitable development}

Inclusiveness implies the enlargement of the Caribbean Community to bring in the other islands, and the widening of trade arrangements to include the Caribbean Sea economies, consisting of a market of 40 million, inclusive of Cuba. It is proposed, therefore, to include the Dominican Republic as a member of CARICOM and to incorporate the other French and Dutch islands and French Guiana into the CARICOM framework. Inclusive development also implies a new partnership approach to include in the process all actors and agencies in the private sector and civil society organizations to improve the quality of life for all stakeholders.

\section{Transformative and endogenous growth}

Endogenous growth must be based on regional space involving stakeholders at national and regional levels. The drivers of endogenous growth are: growth in the capital sector, capacity to pool regional resources, and the restructuring of domestic and foreign investments/finance. ${ }^{36}$ This implies a transformative approach by:

(i) Fostering a new public-private partnership - endogenous growth should be predominantly private-sector driven. A policymaking fast-track included in convergence will provide the stimulus for the private sector.

(ii) Transformative, endogenous growth means redefining the role of development finance and equity in the Caribbean Sea economic space.

(iii) Endogenous growth implies that production, distribution and competition should be addressed at the same time.

\section{Innovative and entrepreneurial competitiveness}

Building a competitive Caribbean Sea economic space is an absolute necessity for the new frontier of Caribbean convergence. In the current global context, information and communications technologies (ICTs) are central to efficiency and competitiveness. Competitiveness is driven by innovation, both in the areas of science and technology, and in entrepreneurship.

Improving labour productivity and skills in the Caribbean Sea space is crucial. Access to finance, a supportive environment to business and innovation, and the promotion of entrepreneurship and the private sector will enhance the region's potential for capturing a new frontier for Caribbean convergence. Competitiveness is also enhanced by expanding trade and markets across the Caribbean Sea space.

\footnotetext{
${ }^{35}$ Dookeran, W. and Malaki, A. (2013), "A New Frontier for Caribbean Convergence."

${ }^{36}$ James, Vanus (2013), 'Comments on the Convergence Model of Integrated Production'. Symposium to discuss the paper: "Introduction to the Convergence Model of Integrated Production." ECLAC Subregional Headquarters for the Caribbean, Trinidad and Tobago, May 9, 2013.
} 


\section{Adaptive and realigned institutions}

Institutions are key mechanisms for the execution and sustainable nature of convergence. If sustainability of action is critical to convergence, then the roles of adaptive institutions become central. It means realigning existing regional institutions to achieve Caribbean Sea convergence in a sustainable way. It also implies a reorientation of policy imperatives to align the regional institutions to the convergence outcome. There are a number of regional institutions that can become the modalities of execution.

\section{Critical convergence strategies ${ }^{37}$}

A careful review of the various ideas and solutions put forth so far has identified four broad convergence strategies to support the pillars of the Caribbean Sea economy: finance, clustering, infrastructure and production. These strategies are mutually interdependent and, therefore, need to be addressed together. The whole convergence process rests on executing these strategies. While these may appear to be broad regional strategies, the specifics must be closely studied and spelled out by the research and policy groups that are proposed in the policy imperatives.

\section{Financial convergence strategy}

The economic convergence process will have to confront political challenges and the redesign of the economic and financial architecture. Finance and liquidity are the lifeblood of any economic system (national, regional or global). The task is to shore up sufficient regional finance to ensure there is enough liquidity to support convergence. There are four ways of achieving this financial convergence strategy: buffers, capital mobility, a regional stock market and development finance.

Buffers are internally generated and shored up as sovereign wealth funds and international reserves. The other form of buffer is that which is externally supportive of small States and exists in terms of international institutions. These forms of regional and national buffers provide the necessary flexibility to adjust to a new frontier of Caribbean convergence. The requirement of national buffers will discipline the fiscal policy of the respective economies of the Caribbean Sea. Furthermore, these economies will need to engage other Latin American countries and emerging markets to find new buffers. ${ }^{38}$

The creation of a regional stock exchange is an added advantage in expanding regional production, trade and equity markets. There must be a fully-integrated capital market, the free flow of capital, and open investment strategies, accompanied by a review of double taxation treaties. ${ }^{39}$ This will require the review and harmonization of the rules that facilitate movement of capital in the Economy of the Caribbean Sea. The financial sector in the Caribbean has a gross worth of 350 per cent of gross domestic product and yet there is a serious deficit in the area of public financing. 40

${ }^{37}$ Dookeran, W. and Malaki, A. (2013), "A New Frontier for Caribbean Convergence".

${ }^{38}$ Gonzales, Anthony P, 'Assessment of the Convergence Model of Integrated Production'. Symposium to discuss the paper: "Introduction to the Convergence Model of Integrated Production". ECLAC Subregional Headquarters for the Caribbean, Trinidad and Tobago, May 9, 2013.

${ }^{39}$ Dookeran, Winston, Introducing the Convergence Model of Integrated Production. Concept Paper presented at the Meeting of Regional Integration Bodies in the Margins of ECLAC, 7-9 March 2013, Bogota, Colombia. Dookeran, Winston, Address at the Trinidad and Tobago Manufacturers' Association $57^{\text {th }}$ anniversary celebrations. April 2013.

${ }^{40}$ Dookeran, Winston, Address at the Conference on Global Governance and Reform of the International Financial System: Impact on the Americas. Organization of American States, Washington D.C. April 22, 2013. 
Therefore, convergence will also require redefining the role of the development finance institutions that must respond to the needs of a new convergence process.

\section{Resource-clustering convergence strategy}

Clustering is the regional grouping of firms and institutions. It is an array of collaborating and competing services and providers that creates a specialized infrastructure supporting the industries and businesses. Typically, clustering draws upon a shared talent pool of specialized skills and/or resources. Clustering signifies a synergized, dynamic relationship between companies, stakeholders, institutions and economies in the Caribbean. ${ }^{41}$ It contributes to regional networking through publicprivate partnerships.

Regional clusters have the ability to offer local goods and services, knowledge and linkups that cannot be matched by outside rivals. In this way, clustering can contribute to innovative competitiveness and transformative, endogenous growth. Clustering relates to production integration that will enhance regional competitiveness and value-added manufacturing and services. It means the clustering of regional resources to consolidate growth, innovation and competitiveness. For instance, regional branding of products and multi-destination tourism are ways of clustering.

Clustering would also mean a regional strategy for capital mobility, foreign direct investment to facilitate the regional transfer of knowledge, skills and technology, regionally-based and -owned investments for promoting innovation, and a regional strategy for ICTs and data exchange. There are synergies in clustering universities and technical institutions in the region - such as partnering for innovation and competitiveness. Clustering is about complementarities in convergence in the Caribbean Sea economic space. Pooling of resources could precipitate faster-and more sustainedgrowth, which could then spill over to impact all other countries. It could also imply Caribbean convergence of capital, with resource-rich countries driving the process.

\section{Infrastructural convergence strategy}

The infrastructure for the new frontier of Caribbean convergence includes terrestrial transport linkages, aerial linkages and communications technology with cross-border capability, border management and security, and the regulation of movement of people. Improved, low-cost regional transport (such as by liberalizing and encouraging regionally-based/-owned low-cost carriers to compete) is absolutely critical to facilitating the greater movement of goods and people within the Caribbean. Endogenous growth also needs improved labour productivity, especially targeting youth and addressing equality and equity that benefits all stakeholders. Improving infrastructure facilitates quicker, and cheaper, movement of goods, services and people.

Regionally-owned (private and/or public), low-cost air carriers operating in the economy of the Caribbean Sea will boost trade, production, and multiple tourism destinations. This, in itself, will promote entrepreneurship and business opportunities across the economic space - a kind of multiplier effect that will lock in the private sector. There is tremendous scope for public-private partnerships in developing Caribbean convergence infrastructure (universities, research centres, hospitals, air and sea transportation networks, and telecommunications networks).

${ }^{41}$ Porter, Michael (1998), 'Cluster and the New Economics of Competitions'. In Harvard Business Review, Nov-Dec 1998. 


\section{Industry and production convergence strategy}

A strategy of production integration is central to all pillars of the Economy of the Caribbean Sea. ${ }^{42}$ The emphasis is on private-sector -led production integration. The important issue here is to design appropriate modalities to stimulate private-sector response. These modalities need to be incorporated in the partnership approach. Including the private sector as stakeholders in the new public-private partnership would invigorate the private sector.

The public-private partnership needs to be accompanied by a Caribbean investment programme designed to foster production, distribution and integration across the convergence space. This will stimulate subcontracting and outsourcing of manufacturing and services which, in turn, will reinforce entrepreneurship and competitiveness across the Caribbean Sea economic space.

In creating a new frontier for Caribbean convergence, production integration, buttressed by capital mobility and regional equity markets, will unleash a whole new regional economic dynamism. Encouraging regional value chains would link the internationalization decisions of the leading economic players with the convergence process. ${ }^{43}$ The strategy should focus on reducing transactional costs and coordinating the supply of regional public goods to generate regional value chains. ${ }^{44}$

42 Dookeran, W. (2013), "Introducing the Convergence Model of Integrated Production." Caribbean Journal of International Relations \& Diplomacy (a joint quarterly publication of the University of the West Indies Institute of International Relations and the Trinidad and Tobago Ministry of Foreign Affairs), Volume 1, Issue 2, June 2013.

43 United Nations Economic Commission for Latin America and the Caribbean (ECLAC), (2010), Opportunities for Convergence and Regional Cooperation. High-level Summit of Latin America and the Caribbean. February 21-23, 2010, Cancun, Mexico.

44 Latin American and Caribbean Economic System (SELA) (2012), Productive development and industrialization in Latin America and the Caribbean. Permanent Secretariat of SELA, Caracas, Venezuela, July 2012, SP/Di No. 18-12. 


\section{Drilling down for development}

\section{A. Institutional convergence drivers}

The convergence framework includes adaptive institutions as a pillar of convergence. Existing delivery instruments will need to be realigned to adapt to the convergence process. Therefore, the following existing institutions and organizations that can serve as modalities of execution towards a new frontier of Caribbean convergence have been identified:

- The CARICOM Secretariat - as the principal administrative organ of CARICOM - should 'devise a Marshall-like strategic development plan to propel economic recovery." ${ }^{45}$

- The Caribbean Development Fund, created under the Revised Treaty of Chaguaramas (2001), provides technical and financial assistance to address regional asymmetries among CARICOM members.

- The Latin American and Caribbean Economic System (SELA) - established in 1994 provides consultation and coordination for the adoption of common positions and strategies to foster cooperation and integration among countries in Latin America and the Caribbean.

- The Association of Caribbean States (ACS) was established in 1994 to strengthen the regional cooperation and integration process with a view of creating an enhanced economic space in the region.

- The Caribbean Sea Commission was established in 2008 under the auspices of ACS to share information, provide advice and build consensus among partners in the wider Caribbean region over ocean governance.

- The United Nations Economic Commission for Latin America and the Caribbean (ECLAC) - to which the Caribbean was included in 1984 - is the central entity on issues of the region as a whole and for policy.

- The Council for Trade and Economic Development (COTED) - under the auspices of CARICOM secretariat - promotes issues of trade and economic development in the region

\footnotetext{
${ }^{45}$ The recently-appointed ambassador of Trinidad and Tobago to CARICOM, Dr. Clarence Henry
} 
- The Caribbean Growth Forum (CGF) - launched in 2012 - is a platform for public-private dialogue around the growth challenge. It engages a broad group of stakeholders and critical players including the private sector and civil society.

\section{B. Twelve-point action proposal for Caribbean convergence ${ }^{46}$}

It is now necessary to design and engineer catalytic drivers to propel structural and institutional changes. Restructuring of the CARICOM secretariat alone is not enough: there is need for an additional catalyst, on a more permanent basis, to drive the process/structure and include the private sector. This is only the starting point of the narrative for speeding up the process in a strategic direction which involves inclusiveness, rationalization and improved management.

This framework - the moving towards a new frontier of Caribbean convergence - has generated some policy imperatives that require immediate attention and decision at this meeting: therefore, the CARICOM foreign ministers hereby recommend the adoption of the following twelvepoint proposal for action - with immediate effect - to move the process in the direction of a 'new frontier for Caribbean convergence,' to establish the 'Economy of the Caribbean Sea':

\section{Expand the political and economic space}

Support and approve the expansion of CARICOM into the Economy of the Caribbean Sea:

- Recommend a fast-track decision to facilitate the entry of the Dominican Republic as a member of CARICOM.

- Endorse the incorporation of the Dutch and French Caribbean islands and French Guiana into the CARICOM framework.

\section{Develop a Caribbean Sea convergence integrated transport logistics policy}

Reiterate that transport and logistics are critical to achieving transformative, endogenous growth and competitiveness in the Economy of the Caribbean Sea:

- Propose a ministerial meeting calling for all airlines operating in the region to consider how the logistics of transport could be rationalized to provide better interconnection.

- Propose that this meeting look at low-cost air carriers involving the region's private sector, and/or public-private partnerships to this end.

- Establish a regional research group to look at sea transportation and make recommendations for providing a system of sea transportation within the Economy of the Caribbean Sea.

\section{Establish a Caribbean Sea convergence capital mobility policy}

Endorse finance and capital mobility as the backbone for sustaining the pillars of convergence of the Economy of the Caribbean Sea. Reiterate that there must be a fully-integrated capital market and the free flow of capital:

- Propose that a single capital market should be established. Therefore, mandate all stock exchanges in the region to meet and work out the modalities within an agreed time frame.

- Recommend that all members of the Economy of the Caribbean Sea create national sovereign wealth funds and regional buffers as measures to offset external shocks.

\footnotetext{
${ }^{46}$ See Dookeran, W. and Malaki, A. (2013), “A New Frontier for Caribbean Convergence.”
} 
- Set up a regional committee to review and harmonize mechanisms to facilitate intraregional investment. Organize a regional meeting of all private-sector organizations to identify areas and strategies of production integration and public-private partnership.

\section{Develop Caribbean Sea convergence energy and food security policies}

Reaffirm that energy and food security are essential for the convergence of the Economy of the Caribbean Sea:

- Set up a policy group to develop a common energy security plan, firstly to define clearly the rules for complementarities in the use and clustering of regional energy and natural resources for a new frontier of Caribbean convergence; and secondly to ensure that regional resources will be utilized for strengthening production integration and competitiveness.

- Set up a policy group to examine a common policy on self-sufficiency in food.

\section{Implement a Caribbean Sea convergence financial policy}

Agree that development financial institutions are isolated and their modus operandi compartmentalized into public and private sector:

- Propose that all the development finance institutions in the region - the Caribbean Development Bank, the Inter-American Development Bank, the Development Bank of Latin America (Corporación Andina de Fomento), and others - meet to redesign their lending paradigm in the region to deal with the current problems and support the convergence process.

- To bring together development finance institutions to redefine the role of development finance that is sensitive and supportive to regional needs and the convergence process.

\section{The role of Trinidad and Tobago in Caribbean convergence ${ }^{47}$}

In support of convergence, Trinidad and Tobago and the wider Caribbean region should be committed to the creation of an agile foreign service that showcases their unique location within the family of nations. New politics also require a new approach to foreign relations, ${ }^{48}$ since an effective foreign policy is the pursuit of national objectives, policies and plans in the international arena. Trinidad and Tobago - and the region - must open up and maintain its own space in the twenty-first century's information-driven global environment. Foreign policy must be aligned with well-defined national priorities, and its core objectives must be understood, first and foremost, as the pursuit of sustainable human development objectives through concerted action at the international level. The image of Trinidad and Tobago and the region is really the most valuable asset and must be protected at all costs.

${ }^{47}$ Based on a speech by Winston Dookeran, entitled, "Caribbean Convergence: Revisiting Caribbean Integration."

${ }^{48}$ It assumes that Trinidad and Tobago is an integral part of the one-world information-driven environment: it requires an interconnected Trinidad and Tobago through our connection to the world wide web of information technology platforms; an interrelated Trinidad and Tobago through international relationships both formal and informal; an interactive Trinidad and Tobago through our active participation in the global market, through trade and travel; and an integrated Trinidad and Tobago by a clearly-formulated foreign policy that has our national interest in its core. These four dimensions must be managed to shape and improve the image of the country. The various interest groups and stakeholders must be included in building the new image of Trinidad and Tobago as a genuinely progressive country. 
The core objective of the new foreign policy must be that the national interests of the Caribbean Sea convergence region become the drivers of our new national images. What actions must Caribbean Sea States take to restore and align current and future national interests to build a sustainable national image? Foreign relations must be based on certain basic principles:

(i) Restore the moral voice of Trinidad and Tobago in the international community as a beacon of human rights and respect for the rule of law.

(ii) Ensure that the stain of corruption which has tarnished our national image internationally be tackled as a matter of urgency, to restore confidence among the international investment community, IDB, World Bank, IMF, OAS, European Union and bilateral partners.

(iii) Pursue vigorously the inclusion of drug trafficking as an element of crime against humanity in the statues of the international criminal court (ICC) of which Trinidad \& Tobago was a major player in its formation.

(iv) The Institute of International Relations at the University of the West Indies is the major training ground for our foreign-service personnel in all aspects of the craft and challenges of diplomacy in this verbalized world. The region should seek partnerships with some of the best institutes of diplomacy in the hemisphere.

We are blessed with an extraordinarily talented people who must be at the centre of our efforts to impact the world with our unique talents and skills. To fulfil this, we must unite with our Caribbean neighbours for the common good of all Caribbean peoples: this unity must be strong enough to contain the individual aims of members. The future of our small Caribbean States depends, not so much on the proliferation of interregional and intraregional organizations - at enormous cost and duplication of effort - but rather, on a genuine effort to negotiate, and find, common ground. Most importantly, we have to come to terms with our severe limitations as small island States, by complementing each other's strengths when we negotiate with the rest of the world.

At the international level, our Government must ensure that our diplomatic missions abroad are seen, less as a place for retired politicians elevated to the post of ambassador - sending the wrong message to those with whom we hope to negotiate benefits for Trinidad and Tobago - but instead as well-trained diplomats, highly respected and capable of using their diplomatic skills for the benefit of all sections of the population of Trinidad and Tobago: for the farmer, the fisherman, the dancer, the singer, the craftsman, the scholar and every other citizen, business establishment and organization that has something good to offer the world.

The limits to Caribbean integration - in its orthodox definition - may have been reached. It may become an absolute requisite - for the development and integration prospects of the region - to broaden that economic space to our geographical position in Latin America, as well as to the changing dynamics of the world order.

"As we search for more economic space, Caribbean convergence is an issue that we need to look at in the context of an ever-changing global arena."

\section{[Dookeran, W.]}

No longer can we rely on what has to be done. We must now find the mechanics to make it happen and the Caribbean Sea convergence model seeks to do just that. This is the challenge facing the region and all institutions that promote Caribbean integration within the region. The Caribbean Development Bank is one such institution with this pivotal role but, at the same time, it must provide the leadership that is required for opening up wider economic space in the region as well as deepening the convergence process in our economic framework.

On this score, we cannot ignore the absolute necessity of dealing with the very important issue of innovation. Professor Michael Porter believes that our survival as individual nations and, indeed, 
as a region in a new age of innovation-driven economy, rests on exploring the interconnectivity of our economies, on how best we can use it to build a stronger competitive advantage. ${ }^{49}$

He emphasizes that the nation's neighbours are our natural trading and investment partners and the natural part of internationalization of local firms in the neighbourhood.

\section{Synergy of economic logic and political logic}

A stronger competitive advantage is predicated on the issue of entrepreneurship. Unfortunately, the traditional private business sector tends to be risk-adverse and, with the choices before them, has less interest in moving onto the development path. This new entrepreneurship calls upon the private sector to change its own perspective towards the country. No longer is the framework one in which to say to Governments, 'What I can get,' but rather, 'What I can be.' These are the deeper issues underlying the development strategy before us; but, in the final analysis, it is important that opportunities be created for dialogue and action.

It is often believed that development is a technical matter, that solutions can be based on professional and technical analysis: but this can only happen if there is a deeper appreciation of the development politics that make things possible.

Sustainable development is indeed a process in which there must be synergy formulated between economic logic and political logic - measures which are needed to pursue economic efficiency in both the international and regional spheres alongside the political logic now required to make it happen. This will ensure that the adjustments in the politics are appropriate to the requirements of the economic logic.

\section{E. Closing the expectation/performance gap}

The growing gap in the Caribbean between expectations and performance, and the rising tension between intention and reality, has widened the space between the art of politics and the discharge of governance. Political rhetoric tends to base new promises on old premises. In this politics of illusion, past hopes remain unfulfilled and tentative new hopes have little expectation of action. Whatever programmes we develop, therefore, must bring political and economic logic together.

Governments in both the developed and the developing world are facing the increasingly difficult task of managing their national economies in order to improve macroeconomic performance,

${ }^{49}$ Porter, Michael (1998), “Cluster and the New Economics of Competitions.” In Harvard Business Review, Nov-Dec 1998.

Professor Michael Porter is the author of 18 books and numerous articles including: Porter, M.E. (1980) Competitive Strategy, Free Press, New York, 1980, voted the ninth most influential management book of the twentieth century in a poll of the Fellows of the Academy of Management; (1985) Competitive Advantage, Free Press, New York, 1985; (1990, 1998) The Competitive Advantage of Nations, Free Press, New York, 1990; and (1998) On Competition, Boston: Harvard Business School, 1998; M.E. \& Kramer, M.R. (2006) "Strategy and Society: The Link Between Competitive Advantage and Corporate Social Responsibility", Harvard Business Review, December 2006. He is a leading authority on competitive strategy and the competitiveness and economic development of nations, States, and regions. His work is recognized by many Governments, corporations and academic circles globally. He chairs the Institute for Strategy and Competitiveness at Harvard Business School and leads the programme for newly-appointed Chief Executive Officers of very large corporations. 
increase public investment in job creation, education and health care, and develop policies and institutions to address the issues of poverty and inequality.

In our own region, we need to renew the strategies that will provide us with buffers against external shocks and, at the same time, generate triggers for sustainable economic growth. In this respect, there is a real need to understand the power culture that is holding back growth and development in the region. It has been argued that the anti-growth coalition ${ }^{50}$ is so deeply embedded in the socioeconomic and political culture of small States that any development strategy must break that anti-growth coalition before any growth and development can take place.

These are issues that will ensure that the political logic and the economic logic work together as we embark on a programme to give the Caribbean Development Bank and Caribbean integration efforts a new, quantum leap into challenging and confronting future insecurities. No doubt the agenda is enormous, but we can neither succumb to the forces of history, nor surrender to the new vulnerabilities that will surface in the path ahead.

We have tried to chart out a new strategy of Caribbean convergence cast against the backdrop of an emerging global political economy. It is a regional strategy that aspires to bring benefit in the future. Finally, we need to reiterate that, while CARICOM may have reached its limit, there is another, better, way of moving the process forward through Caribbean convergence. The task ahead is not an easy one, but it can be accomplished through the synergy of economic logic and political logic.

${ }^{50}$ Professor Avinash Persaud first coined the term anti-growth coalition and elaborated on it in Power Politics and Performance (Dookeran \& Jantzen, 2012). 